\title{
89 Sports medicine screening examinations
}

Medical screening by a sports physician is necessary to prevent physical activity from damaging health and is highly advisable

- from the age of 35 years, after longer periods of physical inactivity,

- in apparently healthy persons with one or more risk factors,

- after recovery from any serious illness.

The medical screening examination by a sports physician should cover the patient's general and exercise-related medical history, including a physical examination at the least. Special attention should be paid to any increased risk for cardiovascular diseases. Patients with serious acute or chronic diseases, regardless of the cause, should avoid sports. Over-ambitious athletes, determined to achieve their sporting goals at all costs, are more likely to ignore common sense when suffering from a febrile infection.

Fever, however, is an absolute contraindication to engaging in physical activities.

Mild chronic diseases or congenital organic impairments often dictate the necessary limitations. Anyone known to have such health-related disorders should discuss with their doctor whether or not physical exertion is advisable. If so, a personalized training regimen, adapted to the person's physical circumstances, should be developed in consultation with a sports physician. As studies on exercise ther-

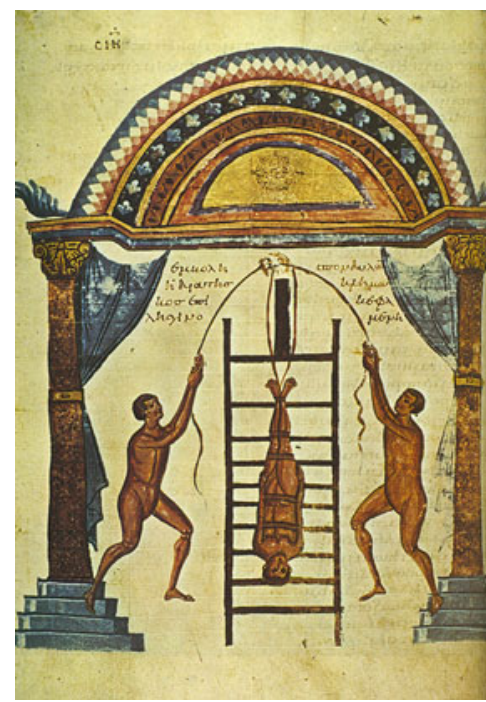

- Fig. 89.1 Treatment of a spinal dislocation. (courtesy of Andreas Verlag, Salzburg)

apy have shown, patients usually benefit greatly by participating in competently supervised sports rehabilitation programs for cardiovascular diseases, cancer or diseases of the musculoskeletal system (Chiaranda et al. 2013).

One special parameter of screening programs for persons over 65 years of age is to measure their treadmill walking speed. The faster they can walk, the fitter and stronger they are, and the longer they tend to live as well. These are the findings based on data from 9 cohort studies on over 34,000 persons and observation periods of between 6 and 21 years (Studenski et al. 2011). 